\title{
Transdisciplinarity within the academic engineering literature
}

\section{S. Lattanzio*, E. Carey and A. Hultin}

The University of Bath, Bath, BA2 7AY, UK

Email: s.lattanzio@bath.ac.uk

Email: emcc20@bath.ac.uk

Email: aeoh20@bath.ac.uk

${ }^{*}$ Corresponding author

\section{R. Imani Asrai}

The University of Bristol, Bristol, BS8 1TH, UK

Email: reza.imaniasrai@bristol.ac.uk

\section{McManus and N. Mogles}

The University of Bath,

Bath, BA2 7AY, UK

Email:mm291@bath.ac.uk

Email:nmm38@bath.ac.uk

\section{G. Parry}

The University of Surrey, Guildford, GU2 7TE, UK

Email: g.parry@surrey.ac.uk

\section{L.B. Newnes}

The University of Bath, Bath, BA2 7AY, UK

Email: enslbn@bath.ac.uk

\begin{abstract}
Despite increased discourse around transdisciplinary (TD) research, there is a perception it has received less attention within engineering. This is significant if, as generally accepted, TD increases the societal value of research. This paper benchmarks TD engineering research against the broader TD literature, addressing the question: How do the characteristics of the academic engineering TD literature compare to the TD academic literature in general? We analyse the chronology, source journals, and text of papers referencing TD within their abstract and compare this to papers that fall within the engineering subject area. The conclusions find that TD research is limited generally, and within engineering specifically. Historically, TD research focuses on
\end{abstract}


sustainability challenges, a persistent trend within the general literature. Within engineering research, the focus of TD is wider and addresses operational and 'grand challenge' problems. TD remains poorly defined and future work should focus on clarifying meaning within the engineering discipline.

Keywords: transdisciplinary; trans-disciplinary; transdisciplinarity; engineering research; characterising transdisciplinarity; characterising transdisciplinary research; benchmark; societal value.

Reference to this paper should be made as follows: Lattanzio, S., Carey, E., Hultin, A., Asrai, R.I., McManus, M., Mogles, N., Parry, G. and Newnes, L.B. (2020) 'Transdisciplinarity within the academic engineering literature', Int. J. Agile Systems and Management, Vol. 13, No. 2, pp.213-232.

Biographical notes: S. Lattanzio is a Research Associate within the TREND (TRansdisciplinary ENgineering Design) research group at the University of Bath. Her PhD thesis created an approach for managing the performance of decision support tools used in asset management. It was a collaboration between the Engineering and Physical Sciences Research Council, National Grid and the University of Bath.

E. Carey is a Research Associate within the TREND (TRansdisciplinary ENgineering Design) research group at the University of Bath. Her PhD thesis investigated the need to support efficient access to information and knowledge in complex engineering projects. It was a collaboration between the Engineering and Physical Sciences Research Council and the University of Bath.

A. Hultin is a Research Associate within the TREND (TRansdisciplinary ENgineering Design) research group at the University of Bath. His research areas are focused on networks analyses and machine learning alongside the data challenges these present. His current research is focused on collaborative knowledge systems.

R. Imani Asrai is a Research Associate and Lecturer within the TREND (TRansdisciplinary ENgineering Design) research group at the University of Bristol. He received his BSc and MSc in Mechanical Engineering at Sharif University of Technology Tehran, and his $\mathrm{PhD}$ in Mechanical Engineering at University of Bath, Bath.

M. McManus is a Professor within the Department of Mechanical Engineering at the University of Bath. She has a particular interest in sustainability and life cycle impacts. Her research enables her to work with engineers to determine the environmental impact of different systems, with particular regard to renewable energy production. She is academic member of the TREND (TRansdisciplinary ENgineering Design) Research Group.

N. Mogles is a Research Associate within the TREND (TRansdisciplinary ENgineering Design) research group at the University of Bath. She received her MSc in Cognitive Science and PhD in Artificial Intelligence at VU University Amsterdam.

G. Parry is Professor of Digital Transformation at the Centre of Digital Economy [CODE], Surrey Business School, University of Surrey. His work is characterised by an approach of partnering with organisations to develop creative solutions to challenges. He is interested in understanding what makes 'good' business. He undertakes both qualitative and quantitative studies 
focusing upon process mapping and visualisation of data, business models, value capture, servitisation, and supply chains. He has managed research consortia within the automotive, aerospace, music and construction industries and has published and edited numerous international journals.

L.B. Newnes is Head of Costing Research within the Department of Mechanical Engineering, at the University of Bath. Her research focuses on through life costing from concept design through to the in-service/in-use phases. The sectors/application areas for her activities include; aerospace, defence, medical device design, modelling uncertainty in through life costing, modelling in-service costs and trade-off analysis between specification and cost. She is the Principle Investigator of the TREND (TRansdisciplinary ENgineering Design) Research Group which is funded by the UK's Engineering and Physical Sciences Research Council (EPSRC).

\section{Introduction}

The current research funding environment increasingly places an expectation that scientific research should deliver benefit for society (Carr et al., 2018; Gulbrandsen et al., 2011; Heimeriks et al., 2008; Hessels and Van Lente, 2008; Mowery et al., 2001). To achieve this twin hurdle of academic rigour and relevance to society numerous alternative science systems have been proposed (Pettigrew, 1997). These include finalisation science (Böhme et al., 1983), strategic research/strategic science (Irvine and Martin, 1984), post-normal science (Funtowicz and Ravetz, 1993), new production of knowledge (Gibbons et al., 1994), innovation systems (Edquist, 1997), academic capitalism (Slaughter and Leslie, 1997), post-academic science (Ziman, 2000), and triple helix (Etzkowitz and Leydesdorff, 2000). At the core of all of these systems is that they should be transdisciplinary (TD). That is, they should go above and beyond the scientific disciplines to interact or incorporate non-scientific expertise (Hessels and Van Lente, 2008).

Over recent decades accelerating growth has occurred in TD publications, with increased interest from within and outside of academia (Klein, 2014). Despite this ascendancy, within the engineering subject area TD is considered to have received less attention (Wognum et al., 2019; Wognum et al., 2018). Analysis of the papers appearing on Scopus supports this stance with engineering journal papers contributing only $4.1 \%$ of the total TD papers. This is lower than the Social Sciences (26.4\%), Environmental Science (15.0\%), and Medicine (10.9\%), Arts and Humanities (7.4\%), and Agricultural and Biological Sciences (5.1\%) subject areas (Figure 1). This oversight by one of the main scientific disciplines is significant if a TD approach is key to increasing the societal value of research (de Jong et al., 2016; Lawrence, 2015).

Although there is an assertion that TD has received less attention within engineering, little attempt has been made to explore this phenomenon in more detail. This paper addresses that gap. Within this study an analysis of the literature appearing on Scopus is undertaken to address the research question: How do the characteristics of the academic engineering TD literature compare to the TD academic literature in general? 
Figure 1 Comparison of subject area of papers referencing 'transdisciplin*' OR 'trans-disciplin*' within their abstract (see online version for colours)

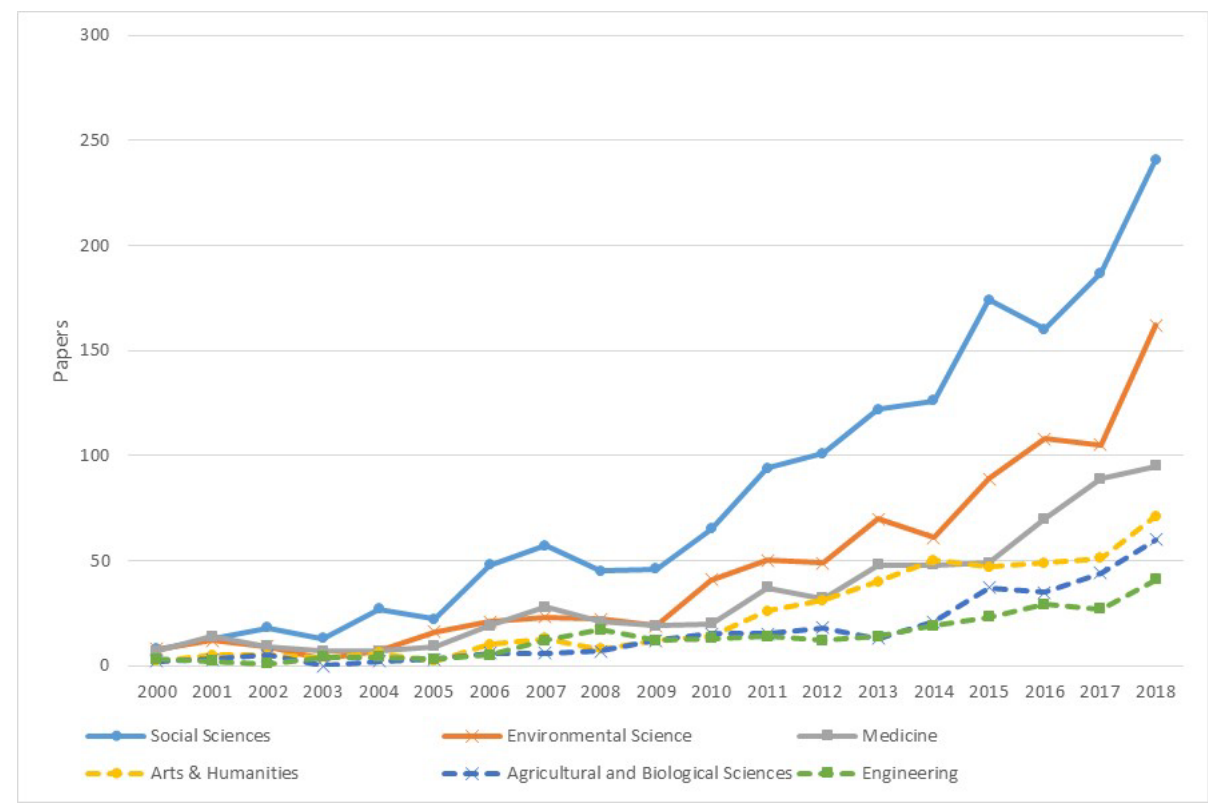

Source: Extracted from Scopus 14/10/2019

The paper is structured as follows: First, the background literature on the origins of TD and the current TD funding environment (Section 2). This review identifies a drive towards TD, but also a gap in benchmarking its use within the academic engineering literature. Next, the method used within the study is detailed. The approach involved comparison of chronology, comparison of journals, and comparison of text of papers which reference TD within their abstract with papers which reference TD and are classified by Scopus as falling within the engineering subject area (Section 3). The results of the study are presented (Section 4) and discussed in light of the literature (Section 5). Finally, conclusions are formulated (Section 6) and future work identified based upon the gaps found in knowledge (Section 7).

\section{Transdisciplinarity}

Since the 1960s, the quest for and application of interdisciplinary (ID) approaches has received much attention amongst both the academic and policy communities (Carr et al., 2018; Huutoniemi et al., 2010; Klein and Falk-Krzesinski, 2017; Raasch et al., 2013). In the 1970s, the emergence of transdisciplinary (TD) as an additional level of disciplinarity added to the discourse. Although without a universally recognised definition, it is generally accepted that TD exceeds ID approaches. Typically, TD involves going above and beyond the boundaries of academic disciplines, and the interaction or incorporation of non-academic stakeholder perspectives (Gibbons et al., 1994; Jantsch, 1970; Pohl and Hadorn, 2007). 


\subsection{Origins of transdisciplinarity}

The origin of TD is generally considered to be in the 1970s. Around this time there was a growing dissatisfaction about the relevance of traditional single disciplinary teaching. In response, there was movement towards ID teaching and research (Bernstein, 2015). At a conference held jointly by the Centre for Educational Research and Innovation (CERI) and the French Ministry of Education (CERI, 1972), Jean Piaget presented a paper which differentiated between single (mono, M), multi (MD) and interdisciplinarity (ID). The paper closed with the statement: 'Finally, we may hope to see a higher stage succeeding the stage of interdisciplinary relationships. This would be "transdisciplinary", which would not only cover interactions or reciprocities between specialised research projects, but would place these relationships within a total system without any firm boundaries between disciplines' (p.138).

At the same conference, Erich Jantsch presented a paper that cross-referenced and expanded upon Piaget's work (CERI, 1972). Jantsch asserted that for education/ innovation to be of value to society it needed to cut across social, economic, political, technological, psychological, anthropological and other dimensions. Using a systems approach, he defined a hierarchical framework which identifies four key levels for consideration within a multi-level, multi-goal education and innovation system: purposive, normative, pragmatic and empirical (Figure 2).

Figure 2 The education/innovation system, viewed as a multi-level multi-goal, hierarchical system (see online version for colours)



Source: Adapted from CERI (1972)

The top of the pyramid is the purposive level: societal meaning and value. Achieving this requires the incorporation of the empirical, pragmatic and normative levels. At the bottom of the hierarchy is the empirical level; the individual scientific disciplines e.g., maths, physics, and psychology. Above this, the pragmatic level is where the theories in individual disciplines are merged and trimmed in order that they become applied e.g., engineering. The next level is the normative level. The normative level is the social systems which have been designed to represent what society considers to be good or desirable e.g., laws, standards and culture. In this way, science in its 'pure' disciplinary 
state is contained only within the empirical level and moving up through the levels places it within the context in which it is conducted.

Although the origins of TD are generally accepted to be in the 1970s, the term remained practically uncited until the 1990s (Bernstein, 2015; Kessel and Rosenfield, 2008).

In the 1990s globalisation and society's growing environmental awareness encouraged the quest for new methods of collaborative working. TD re-emerges, but as two separate schools of thought: The Nicolescuian and the Zurich School (Bernstein, 2015; Augsburg, 2014).

The Nicolescuian School hails from the First World Congress on TD (Portugal, 1994). This conference was led by Basarab Nicolescu during which a Charter for TD was created (Bernstein, 2015). This Charter defined a theoretical ideology for TD which strived towards a 'unity of knowledge' going beyond the disciplines to incorporate ethical, metaphysical and mystical perspectives. The Zurich School adopted a more practical stance. Taking its name from The International Transdisciplinary Conference (Zurich), in 2000, its perspective of TD follows that promoted within the work of Gibbons et al. (1994) and the concept of Mode $2 *$ knowledge creation. Gibbons et al. (1994) recognised a separation between fundamental research motivated by scientific knowledge development within disciplines (Mode 1), and research that was driven by real world problems (Mode 2). *Mode 2 research is undertaken by interdisciplinary teams embedded within the context of application, with knowledge created as a result of problem solving.

To date there is an acknowledged 'plurality of definitions' of TD (Pohl and Hadorn, 2007; Swiss Acadamies of Arts and Sciences, 2018; Lawrence, 2010). What is commonly accepted is that TD comes at the end of a list that starts with multi- (MD) and ends with $\mathrm{TD}$, and in progressing there is an increased confronting of disciplinary boundaries. Where the definitions fail to agree is upon what are the characteristic which would make an approach TD rather than another level of disciplinarity.

\subsection{Funding of transdisciplinary research}

Although not considered mainstream, funding agencies from a number of countries are supporting TD research (Lyall et al., 2015). This support is found both inside and outside of engineering. For example, td-net is an organisation sponsored by the Swiss Academy of Arts and Sciences which has become an influential school for TD research in sciences and humanities (Hadorn et al., 2008). In Australia, the complementary network for TD research focussing on the development of specialised skills for TD researchers, the Integration and Implementation Sciences (I2S) Network is hosted by the Australian National University's (ANU) College of Health and Medicine (CHM) (Bammer, 2013). In UK, the Economic and Social Research Council (ESRC) funded the NEXUS transdisciplinary network on water, energy and food in 2014, as well as the Transdisciplinary Research for the Improvement of Youth Mental Public Health (TRIUMPH) Network in 2018. In USA, the National Institute of Health (NIH) and the National Institute of Food and Agriculture (NIFA) have built TD into the portfolio of research programs (Hunt and Thornsbury, 2014). In Canada, the Canadian Institutes of Health Research (CIHR) promotes TD research in healthcare (Johnson and Hrynkow, 2011). 
Specific to engineering, the recent call of the National Science Foundation (NSF) 'Harnessing the Data Revolution: Transdisciplinary Research In Principles Of Data Science (HDR TRIPODS)' will bring together the electrical engineering, mathematics, statistics, and theoretical computer science communities to develop the theoretical foundations of data science through integrated research and training TD activities. The program will support the development of small collaborative Institutes to facilitate TD research in Big Data (National Research Council, 2014). Additionally, in 2017 the UK Engineering and Physical Sciences Research Council (EPSRC) awarded £1.8M to support manufacturing focussed research aimed at creating resilient transdisciplinary design engineers (The University of Bath, 2018), and in 2019 launched another call to support future manufacturing systems in which it specifically asks for collaboration and fusion of research approaches towards a TD approach (UKRI, 2019).

In summary, there is drive towards TD and there are specific examples of research funders calling for and supporting TD research within engineering. To date however, little effort has been made to benchmarking the current activity.

\section{Method}

The aim of the paper was to provide a benchmark of TD research within engineering. Figure 3 details the research approach.

Figure 3 Research approach

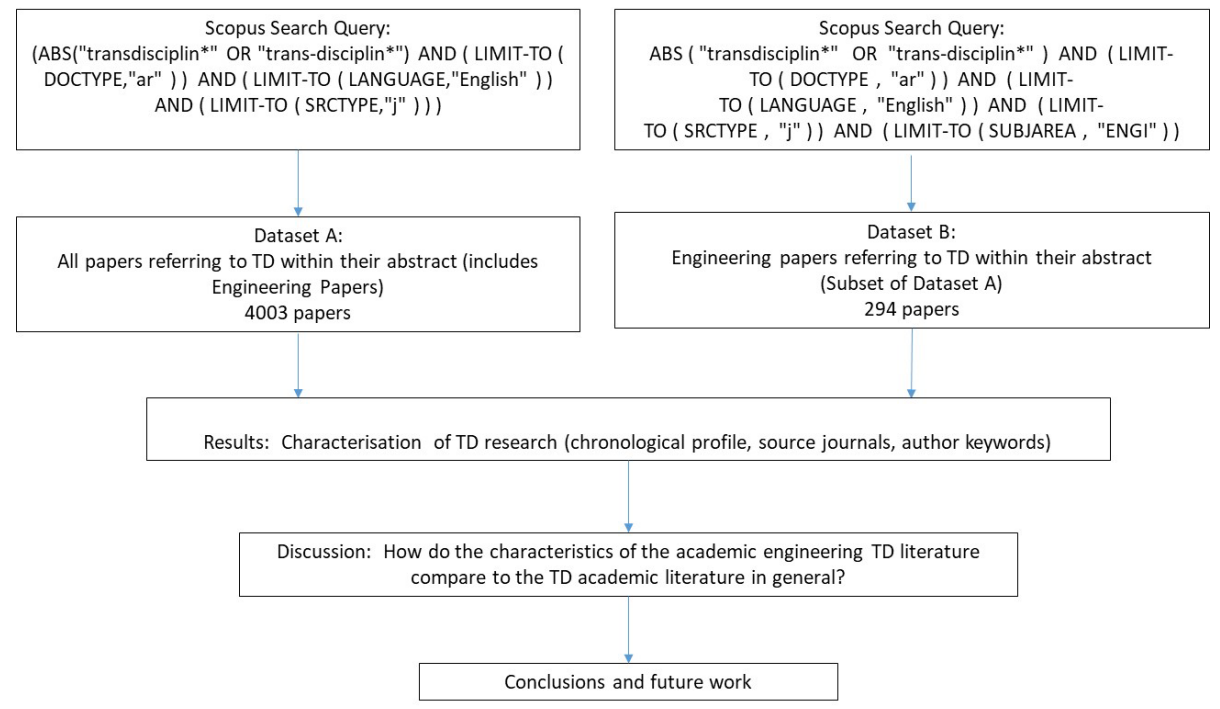

Within this study two dataset were analysed: Dataset A, containing all papers which refer to TD within their abstract; and Dataset B, all papers which refer to TD within their abstract and are categorised by Scopus as falling within the engineering subject area. The use of two datasets allowed comparisons to be made and thus added to the richness of the discussion. The method used to extract these datasets is described within Section 3.1. 
In characterising the papers three factors were considered: In order to demonstrate the extent of the use of the term TD and to observe its emergence over time we look at the chronological profile of the published papers. To explore the focus and whether any themes emerge, an analysis of the source journals publishing TD research. Finally, to understand the content of the papers, a network centrality analysis (NCA) of the Author Keywords. The results of the three analysis were synthesised in order to address the research question: How do the characteristics of the academic engineering TD literature compare to the TD academic literature in general?

\subsection{Extracting the datasets}

Within this work two datasets were analysed. Dataset A, comprising of all TD papers referring to TD within their abstract, and Dataset $\mathrm{B}$, comprising of all papers which refer to TD within their abstract and are categorised by Scopus as falling within the engineering subject area. Both datasets were extracted from Scopus. Scopus is a comprehensive, general academic publication database and was considered preferential to Web of Science (the two most extensive academic databases) as it provided $20 \%$ more coverage and incorporated a wider range of journals (Aghaei Chadegani et al., 2013).

The literature showed there to be a plurality of definitions of TD. In addressing this challenge, when looking to identify TD research a number of approaches have been adopted by researchers. Whilst some have taken the approach of looking at all the research conducted and analysing the data to see which meet their particular definition of $\mathrm{TD}$, others have constructed search queries based on what they believe to be the key terms. For example, Zscheischler and Rogga (2015) identify TD by combining the search terms "transdisciplinarity", "integrative research" and "knowledge integration". To date, no best approach has been identified within the literature. Instead researchers have adopted the approach that is most practical and aligns to their understanding and perspective with regards to TD.

Within this paper, Dataset A (all TD papers), was extracted based on the appearance of the terms 'transdiscipl*' or 'trans-disciplin*' within the abstract. The rationale for using only the term TD was that to date there are no universally accepted proxy terms. The search uses the wildcard '*' to capture any possible ending of this term e.g., transdiscipline, transdisciplinary, transdisciplinarity. To ensure a level of quality the search was constrained to peer-reviewed journal papers, and for accessibility those written in English. Applying this search 4003 papers were returned.

Dataset B (engineering TD papers) used the same terms but in addition limited the extraction to those which Scopus identified as having an engineering subject area. This subset of Dataset A contained 294 papers.

\section{Results}

To characterise the datasets three analysis were undertaken. For ease these are presented separately: the chronological profile of the published papers (4.1), source journals (4.2), and network centrality analysis (NCA) of Author Keywords (4.3). 


\subsection{Chronological profile}

The chronological profile for all TD (Dataset A) shows the term first appearing in 1947 (Jantsch, 1947). However, this is an incorrect entry on Scopus. The first true example of the use of TD within a paper is 1966 (Raab, 1966). Paper numbers remain low $(<10$ papers p.a) until 1993. From the 1990's an increase is seen taking numbers from seven (1990), to 508 (2018) papers (Figure 4).

Figure 4 All papers referencing 'transdisciplin*' OR 'trans-disciplin*' within their abstract (see online version for colours)



Source: Extracted from Scopus 14/10/2019

In contrast, engineering TD papers (Dataset B) were first published in 1980. Papers remain low ( $\leq 1$ paper p.a.) until 2000 . From 2000 a rise is seen, but it is only from the mid-2000s that a sustained increasing trend in publication numbers is seen. This represents a lag of around 15 years between the rise in TD generally, to an increased use of the term within engineering (Figure 5).

Although demonstrating a significant increase, when considering the growth of TD it is necessary to place this in the context of the growth in papers overall. Figure 6 compares the number of TD papers as a percentage of the total number of papers published each year for both datasets.

The normalised results continue to support a claim for growth of TD both in general and within engineering. Prior to 2009 the percentage of TD papers in both datasets is similar. After 2008 the growth in all TD is accelerated in comparison to engineering TD. Despite the rise in papers, as at 2018 as a percentage of all papers produced, TD papers are low. 
Figure 5 Engineering papers referencing 'transdisciplin*' OR 'trans-disciplin*' (see online version for colours)

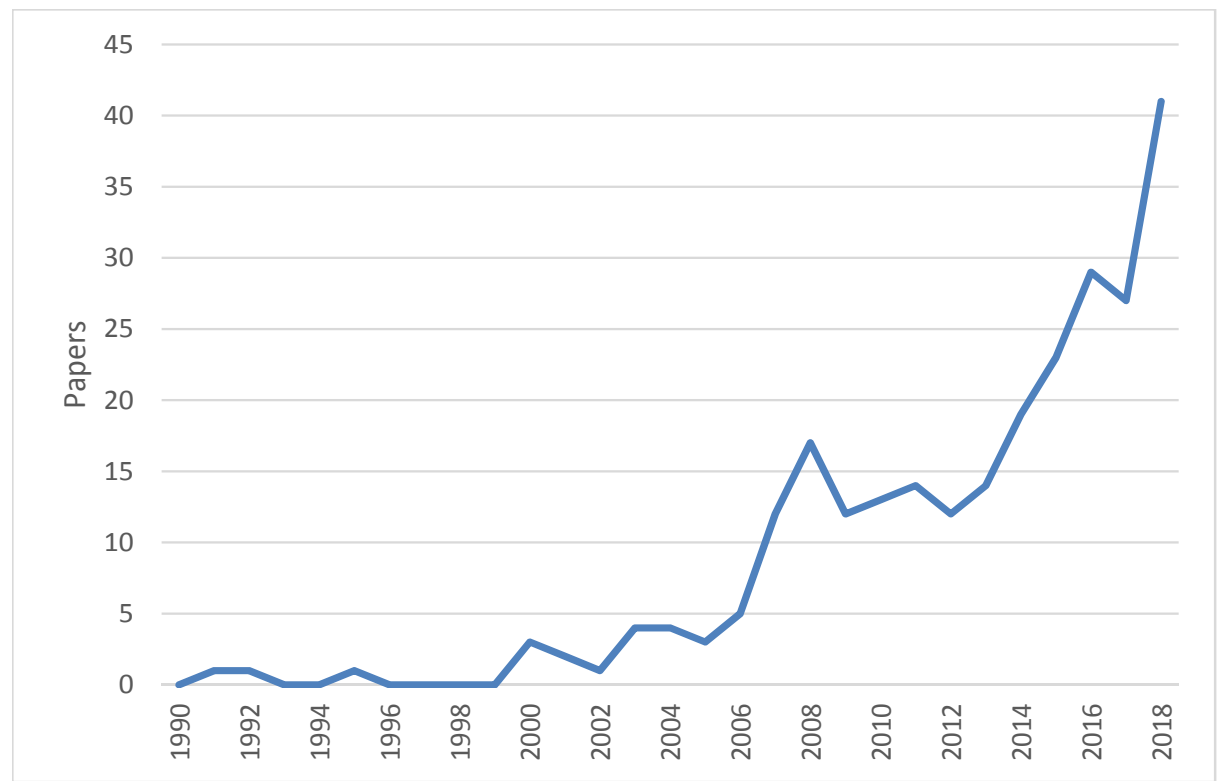

Source: Extracted from Scopus 14/10/2019

Figure 6 Comparison of TD growth as a percentage of overall papers (see online version for colours)

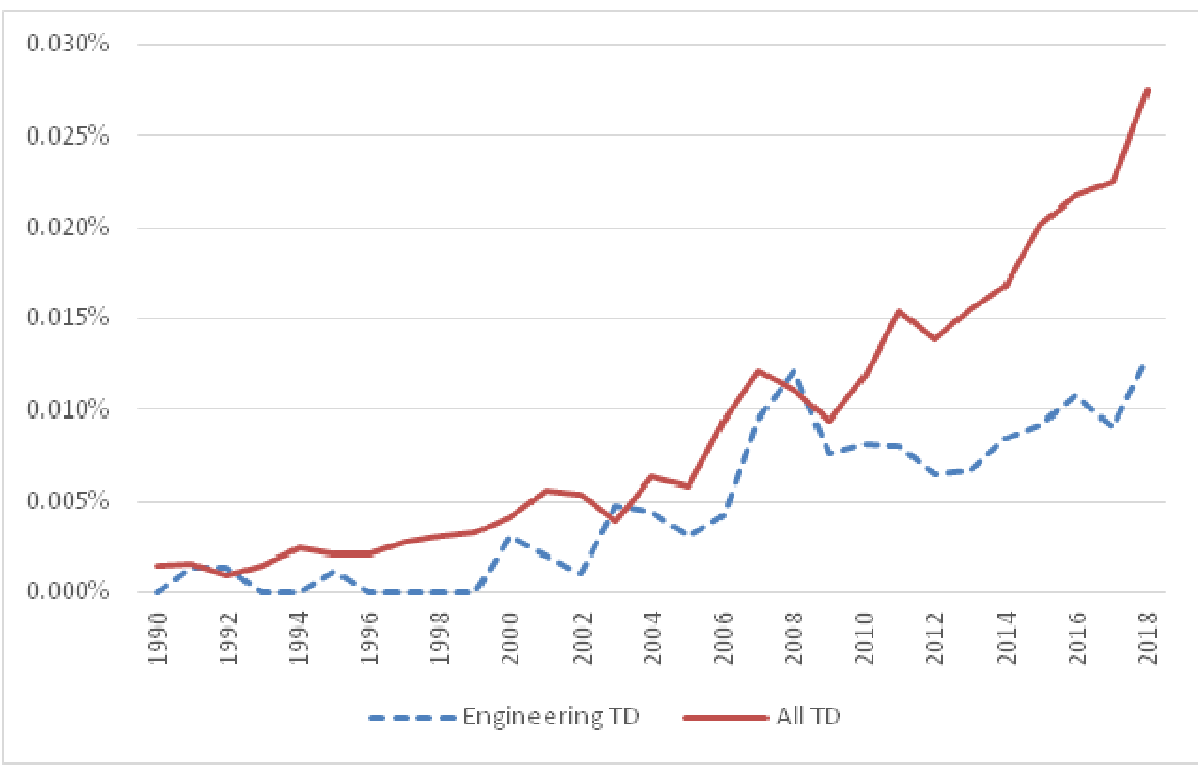

Source: Extracted from Scopus 14/10/2019 


\subsection{Source journals}

Analysis of the source journals for all TD papers (Dataset A) showed them to be widespread (159 journals). Of these the Journal of Aayurveda And Integrative Medicine is dominant with 137 (3.6\%) of the papers. This is followed by Sustainability Switzerland and Sustainability Science with $2.1 \%$ and $1.9 \%$ respectively. The remainder of the top 15 journals, representing $\sim 18 \%$ of the published papers, are listed in Table 1 .

The source journals for all TD (Dataset A) demonstrate a strong environmental and sustainability bias. Indeed, within the top 15 journals, five have either of these words within their title (Sustainability Science, Sustainability Switzerland, International Journal Of Sustainability In Higher Education, Environmental Science and Policy, and Science of the Total Environment), and a further six (Futures, Ecology And Society, Journal Of Cleaner Production, Gaia, Landscape And Urban Planning, Ecological Economics) look to publish papers with this focus. In summary, $\sim 73 \%$ have an environmental or sustainability focus.

Analysis of the source journals for engineering TD papers (Dataset B) identified 114 journals. Although a high number of journals was seen, the spread of these papers was more focussed. Whereas for all TD papers only $\sim 18 \%$ of the papers were published within the top 15 journals, for engineering it is $\sim 49 \%, \sim 15 \%$ of these within one journal, the Journal of Cleaner Production (Table 2).

Table 1 Top 15 journals publishing papers with "transdisciplin*” OR "trans-disciplin*” within their abstract

\begin{tabular}{lcc}
\hline Source title & No. of papers & $\%$ of Total papers \\
\hline Journal of Ayurveda and Integrative Medicine & 137 & $3.6 \%$ \\
Sustainability Switzerland & 80 & $2.1 \%$ \\
Sustainability Science & 75 & $1.9 \%$ \\
Futures & 66 & $1.5 \%$ \\
Ecology and Society & 49 & $1.5 \%$ \\
Journal of Cleaner Production & 43 & $1.3 \%$ \\
Informing Science & 42 & $1.1 \%$ \\
International Journal of Sustainability in Higher Education & 38 & $1.0 \%$ \\
Environmental Science and Policy & 32 & $0.9 \%$ \\
Gaia & 32 & $0.8 \%$ \\
Landscape and Urban Planning & 28 & $0.8 \%$ \\
Ecological Economics & 27 & $0.7 \%$ \\
Kybernetes & 27 & $0.6 \%$ \\
Science of the Total Environment & 22 & $0.5 \%$ \\
Systems Research and Behavioral Science & 22 & $0.5 \%$ \\
\hline
\end{tabular}

Comparing the two datasets the subject matter of the engineering journals is wider. Only five $(\sim 33 \%)$ specifically look to publish research in the sustainability area (i.e. The Journal of Cleaner Production, Kybernetes, Frontiers in Marine Science, Architectural Design, and Building Research and Information). This compares to the eleven ( $73 \%)$ seen within all TD research (Dataset A). Instead, there is a stronger focus on design and 
process (i.e., Journal of Integrated Design and Process Science, Architectural Design) and education (i.e., International Journal of Engineering Education, European Journal of Engineering Education, and IEEE Transactions On Education).

Table 2 Top 15 Engineering journals publishing papers with "transdisciplin*" OR "trans-disciplin*" within their abstract

\begin{tabular}{lcc}
\hline Source title & No. of papers & $\%$ of Total papers \\
\hline Journal of Cleaner Production & 43 & $14.6 \%$ \\
Kybernetes & 27 & $9.2 \%$ \\
Leonardo & 13 & $4.4 \%$ \\
Journal of Integrated Design and Process Science & 10 & $3.4 \%$ \\
International Journal of Engineering Education & 9 & $3.1 \%$ \\
Frontiers in Marine Science & 6 & $2.0 \%$ \\
Architectural Design & 5 & $1.7 \%$ \\
Building Research and Information & 5 & $1.7 \%$ \\
Poiesis Und Praxis & 5 & $1.7 \%$ \\
Footprint & 4 & $1.4 \%$ \\
International Journal of Human Computer Studies & 4 & $1.4 \%$ \\
Acta Astronautica & 3 & $1.0 \%$ \\
Architecture and Culture & 3 & $1.0 \%$ \\
European Journal of Engineering Education & 3 & $1.0 \%$ \\
IEEE Transactions on Education & 3 & $1.0 \%$ \\
\hline
\end{tabular}

\subsection{Network centrality analysis}

Network Centrality Analysis (NCA) provides a ranking of how central a node is to the overall network. This work applies NCA to the Author Keywords. The Author Keywords are the words chosen by the author to best reflect the focus of the paper and thereby provide a key insight into the content of the paper. The NCA results are used as a proxy for identifying the keywords that are most important.

Given that the keywords are chosen by the authors as being the most important to publication and that the keywords can be multiple words (e.g., 'carbon fibre' cannot be broken down into two separate keywords 'carbon' and 'fibre'), no pre-processing other than making the analysis case-insensitive (which may not be consistent) was deemed appropriate.

A network was constructed using keyword cooccurrence (i.e., keywords appearing on the same paper are connected). As such, a network is created by establishing links between keywords that cooccur from the sets of papers. Degree centrality, which utilises the number of neighbours as a definition of centrality, was chosen as the operational definition in this work. To ensure that networks of different sizes can be compared, the degree centrality is normalised by the maximum possible degree $(N-1$, where $N$ is the number of nodes in a network).

The highest ranked 25 keywords for all TD (Dataset A) are presented in Table 3 and engineering TD (Dataset B) in Table 4. 
Table 3 All papers referencing 'transdisciplin*' OR 'trans-disciplin*' within their abstract. Degree centrality analysis of author keywords

\begin{tabular}{lc}
\hline Sustainability & 0.019759 \\
Transdisciplinarity & 0.017829 \\
Interdisciplinarity & 0.015899 \\
Interdisciplinary & 0.011488 \\
Transdisciplinary & 0.010201 \\
Education & 0.008915 \\
Sustainable development & 0.008731 \\
Higher education & 0.006709 \\
Resilience & 0.006709 \\
Transdisciplinary research & 0.006617 \\
Participation & 0.006617 \\
Sustainability science & 0.006341 \\
Climate change & 0.005974 \\
Ecosystem services & 0.005882 \\
Collaboration & 0.00533 \\
Epistemology & 0.005238 \\
Complexity & 0.004963 \\
Research & 0.004687 \\
Learning & 0.004687 \\
Public health & 0.004595 \\
Innovation & 0.004595 \\
One health & 0.004319 \\
Social-ecological systems & 0.004044 \\
Cybernetics & 0.00386 \\
Methodology & 0.003768 \\
\hline
\end{tabular}

Comparing the two datasets (Tables 3 and 4) there are a number of similarities, with 15 of the terms $(60 \%)$ appearing in both lists. Excluding those which are non-informative (transdisciplinarity, transdisciplinary, research, and transdisciplinary research), eleven terms remain (sustainability, interdisciplinarity, interdisciplinary, education, sustainable development, higher education, resilience, participation, epistemology, innovation and cybernetics).

For both datasets sustainability is the highest ranking term. Within all TD (Dataset A) sustainability is a reoccurring topic, with six of the 25 terms $(24 \%)$ considered to fall within this theme (i.e., sustainability, sustainable development, sustainability science, climate change, ecosystem services and social-ecological systems). Within engineering TD (Dataset B) there is less of a bias towards sustainability with only three terms (13\%) considered to fall within the sustainability theme (i.e., sustainability, sustainable development and education for sustainable development). 
Table 4 Engineering papers referencing 'Transdisciplin*' OR 'trans-disciplin*' within their abstract. Degree centrality analysis of author keywords

\begin{tabular}{ll}
\hline Sustainability & 0.027875 \\
Cybernetics & 0.023519 \\
Sustainable development & 0.010453 \\
Interdisciplinarity & 0.010453 \\
Transdisciplinarity & 0.010453 \\
Resilience & 0.008711 \\
Innovation & 0.008711 \\
Interdisciplinary & 0.008711 \\
Transdisciplinary & 0.006969 \\
Computers & 0.006969 \\
Higher education & 0.006969 \\
Design education & 0.006969 \\
Education & 0.006969 \\
Knowledge & 0.006969 \\
Multidisciplinary & 0.006969 \\
Education for sustainable development & 0.005226 \\
Transdisciplinary research & 0.005226 \\
Knowledge transfer & 0.005226 \\
Design & 0.005226 \\
Transdisciplinary engineering & 0.005226 \\
Participation & 0.005226 \\
Research & 0.005226 \\
Creativity & 0.005226 \\
Epistemology & 0.005226 \\
Engineering education & 0.005226 \\
\hline
\end{tabular}

Themes that are identified as having a stronger focus within the engineering TD dataset are: education (i.e., higher education, design education, education for sustainable development and engineering education), which compares to only one term within all TD (higher education), and design (design education and design), where within the all TD dataset none of the top 25 terms are considered to fall within this theme.

\section{Discussion}

Since its origins in the 1990s TD research has been intrinsically linked to sustainability challenges and the overcoming of complex societal problems. Since this time international legislation has been passed which focuses on the reduction of global emissions (CCC, 2019; UK Government, 2008; IPCC, 2019; United Nations, 2019). Engineering products contribute $45 \%$ of global greenhouse gas emissions, with another $21 \%$ ascribed to industries where engineering is also involved to some degree (IPCC, 
2014). Providing a level of analysis which is not seen at other disciplinarities (Stjepandić et al., 2019) it is therefore expected that engineering would be a designated field for TD.

Although it is not possible to demonstrate statistically, there looks to be a $\sim 15$-year lag between the emergence of TD within the general body of literature, to its emergence within engineering. Within all TD (Dataset A) a growth trend is seen from the 1990s, whereas within engineering (Dataset B), this does not occur until the mid-2000s. If this was found to be correct one possible explanation for the lag might be the intrinsic link between TD and sustainability and the later appearance of sustainability journals within the engineering subject area.

The background literature showed that although TD has its origins in 1970, it is the rise in environmental awareness seen in the 1990s which is the catalyst for its increased popularity. In line with the rise in environmental awareness, journals which contain the root word 'sustainab*' first start to appear in 1990, by 1994 there are nine, and by 2003 have increased to 23 . The primary subject area for sustainability journals is Energy, Environmental Science, and Social Science. In contrast, the first engineering journal to have 'sustainab*' within its title (Resource Engineering And Technology For Sustainable World) appears on Scopus in 1994 and it remains the sole title until 2003 when another journal (Sustainable Transport) appears.

Although a later emergence, the question remains as to whether TD has received less attention within engineering. Normalising the number of TD papers as a percentage of the number of papers produced shows that in both all TD (Dataset A) and engineering TD (Dataset B), the number of papers referencing TD are low. By way of comparison if TD papers are compared to the number of papers which reference 'interdisciplin*' on 'interdisciplin*' (ID) or 'multidisciplin*' on 'multi-disciplin*' (MD), TD is significantly less prevalent (Table 5).

Table 5 Disciplinarity of papers in 2018

\begin{tabular}{lccc}
\hline & $T D$ & $I D$ & $M D$ \\
\hline All Subjects & $508(0.03 \%)$ & $3664(0.20 \%)$ & $5906(0.32 \%)$ \\
No. of papers (as a \% of all papers) & & & \\
Engineering & $41(0.01 \%)$ & $318(0.10 \%)$ & $437(0.14 \%)$ \\
No. of papers (as a \% of all papers) & & & \\
\hline
\end{tabular}

Source: Extracted from Scopus

When looking at the source journals all TD (Dataset A) has a strong sustainability bias with eleven of the top 15 journals $(\sim 73 \%)$ having this focus. This would support a hypothesis that sustainability is the driver for the emergence of TD in the 1990s and continues as the major focus. For engineering TD (Dataset B) the source journals demonstrate a wider spread in terms of subject matter, with less of a bias towards sustainability $(5 / 15,33 \%)$. However, in terms of numbers of papers, those published in sustainability focus journals are dominant.

Likewise, the NCA supports a hypothesis that sustainability is an important focus appearing as the top-ranking term within both datasets. That said, similar to the source journals, all TD (Dataset A) was more strongly focussed (6/25, 24\%). Engineering TD (Dataset B) had a wider focus and included increased attention on design and education. 
The wider focus of engineering TD literature is being driven in part by the International Society of Transdisciplinary Engineering (International Society for Transdisciplinary Engineering (ISTE), 2017). Although other TD societies are in existence for example td-net, the Network for Transdisciplinary Research (Swiss Acadamies of Arts and Sciences, 2018) and The Academy of Transdisciplinary Learning and Advanced Studies (ATLAS, 2020), the ISTE is the only international organisation whose focus is solely TD within an engineering context. Established in 2017, the ISTE recognises the increasing complexity of engineering products. New technologies such as additive manufacturing, and the movement towards digitalisation and smart factories bring with them a requirement for the integration of disciplinary skills and a consideration of how this technology will both influence, and be affected by the societal context (Wognum et al., 2018). Within this community, the focus has been on addressing operational and "grand challenge" problems. This is demonstrated by the scope of papers presented within the recent Transdisciplinary Engineering Conference (TE2019). Within this conference, the range of papers included processes to manage the performance of decision support tools within infrastructure organisations (Lattanzio et al., 2019), the automatic generation of digital twins based on scanning and object recognition (Stjepandic, 2019), a mobile stroke unit for rural Australia (Bil and Walter, 2019), efficient design and production of houses (Andre et al., 2019) and industrial systems modelling (Guedes and Borsato, 2019).

\subsection{Limitations}

The literature shows that there are a plurality of definitions for TD and what might be considered to be TD by one, might be considered inter- or multi- by another (Hessels and Van Lente, 2008). This plurality introduces challenges when conducting any studies to understand the use or outcomes of TD research. Although acknowledging the limitations, the method used within this research in which two datasets (all TD and engineering TD) which reference TD within their abstract are compared has value, as it allows a relative comparison to be made.

\section{Conclusions}

The question addressed by this research is how the characteristics of engineering TD research compare and contrast to $\mathrm{TD}$ research in general. Within this study the chronological profile, source journals, and content of all TD research (Dataset A) are compared to TD research conducted in engineering (Dataset B). The results show that in relation to ID and $\mathrm{MD}$, the penetration of TD as a term of use is low both generally, and in engineering research specifically. Traditionally TD has been widely associated with research addressing sustainability challenges. Within the general TD literature this focus continues with analysis of both the source journals and content of the papers identifying sustainability challenges as a strong focus. Although a theme within engineering TD, the bias towards sustainability research is not as apparent and there is a greater focus on design and education. 


\section{Future work}

Funding institutions are increasing focussed on realising societal value from research. It is generally accepted that TD working can increase the relevance and acceptability of research to stakeholders outside of academia. The literature shows there to be an increasing number of papers and examples of funding which specifically support TD research both within and outside of engineering. Despite this positive attention, there remains a plurality of definitions of TD. Although it might be argued there is value in retaining different domain specific TD definitions, when plurality exists within a domain this can cause confusion. This challenge is compounded when the research involves interactions with stakeholders outside academia. In this regard being able to clearly articulate an exact statement for TD within engineering will be key.

Achieving a consensus of TD within the engineering field necessitates having a deep understanding of trends and evolution of constructs. This paper provides one perspective by presenting how the term TD is being used within the engineering academic literature, compare to the academic literature more generally. Future work being conducted within the transdisciplinary engineering design (TREND) Research Group at the University of Bath, will seek to provide other perspectives which add to the richness of the data. One of the areas currently being investigated is the extent to which the academic engineering literature satisfies the conceptualisation of TD provided by Jantsch (1970). Within this research we operationalise the work of Jantsch by creating a coding framework which allows us to classify papers according to their level of disciplinarity (i.e., multi-, inter-, transdisciplinary). This framework is applied to a dataset of engineering papers claiming to be TD. The results of this study will be presented at the International Conference of Transdisciplinary Engineering (TE2020).

\section{Acknowledgements}

The work reported in this paper was undertaken as part of the Designing the Future: Resilient Trans-Disciplinary Design Engineers Project, at the Universities of Bath, Bristol and Surrey. The project is funded by the Engineering and Physical Sciences Research Council (EPSRC) Grant EP/R013179/1.

\section{References}

Aghaei Chadegani, A., Salehi, H., Yunus, M., Farhadi, H., Fooladi, M., Farhadi, M. and Ale Ebrahim, N. (2013) A Comparison between Two Main Academic Literature Collections: Web of Science and Scopus Databases, IDEAS Working Paper Series from RePEc, IDEAS Working Paper Series from RePEc.

Andre, S., Lennartson, M. and Elgh, F. (2019) 'Exploring the design platform in industrialized housing for efficient design and production of customized houses', Transdisciplinary Engineering Conference, Tokyo, Japan.

ATLAS (2020) The Academy of Transdisciplinary Learning and Advanced Studies [Online], Available: http://www.theatlas.org/index.php (Accessed 11 February, 2020).

Augsburg, T. (2014) 'Becoming transdisciplinary: the emergence of the transdisciplinary individual', World Futures, p.70. 
Bammer, G. (2013) Disciplining Interdisciplinarity: Integration and Implementation Sciences for Researching Complex Real-World Problems, ANU E Press.

Bernstein, J.H. (2015) 'Transdisciplinarity: A review of its origins, development, and current issues', Journal of Research Practice, p.11.

Bil, C. and Walter, S. (2019) 'Towards an air mobile stroke unit for rapid medical response in rural Australia', Transdisciplinary Engineering Conference (TE2019), Tokyo, Japan.

Böhme, G., Van Den Daele, W., Hohlfeld, R., Krohn, W. and Schäfer, W. (1983) Finalization in Science: The Social Orientation of Scientific Progress, Springer, Netherlands.

Carr, G., Loucks, D.P. and Blöschl, G. (2018) 'Gaining insight into interdisciplinary research and education programmes: a framework for evaluation', Research Policy, Vol. 47, pp.35-48.

CCC (2019) Net Zero: The UK's Contribution to Stopping Global Warming. London: The Committee on Climate Change, The Committee on Climate Change, London.

CERI (1972) Interdisciplinarity: Problems of Teaching and Research in Universities.

De Jong, S.P.L., Wardenaarc, T. and Horlings, E. (2016) 'Exploring the promises of transdisciplinary research: a quantitative study of two climate research programmes', Research Policy, p.45.

Edquist, C. (1997) Systems of Innovation: Technologies, London, Routledge.

Etzkowitz, H. and Leydesdorff, L. (2000) 'The dynamics of innovation: from national systems 'Mode 2', to a triple helix of university-industry-government relations', Research Policy, Vol. 29, No. 2, pp.109-123.

Funtowicz, S. and Ravetz, J. (1993) 'Science for the post-normal age', Futures, Vol. 25, pp.735-755.

Gibbons, M., Limoges, C., Nowotny, H., Schwartzman, S., Scott, P. and Trow, M. (1994) The New Production of Knowledge, SAGE.

Guedes, G. and Borsato, M. (2019) 'An evaluation of the industrial symbiosis systems modelling', Transdisciplinary Engineering Conference (TE2019), Tokyo, Japan.

Gulbrandsen, M., Mowery, D. and Feldmann, M. (2011) 'Introduction to the special section: heterogeneity and university-industry relations', Res. Policy, Vol. 40, pp.1-5.

Hadorn, G.H., Biber-Klemm, S., Grossenbacher-Mansuy, W., Hoffmann-Riem, H., Joye, D., Pohl, C., Wiesmann, U. and Zemp, E. (2008) Handbook of Transdisciplinary Research, Dordrecht, Springer.

Heimeriks, G., Van Den Besselaar, P. and Frenken, K. (2008) 'Digital disciplinary differences: an analysis of computer-mediated science and 'Mode 2' knowledge production', Research Policy, Vol. 37, No. 9, pp.1602-1615.

Hessels, L.K. and Van Lente, H. (2008) 'Re-thinking new knowledge production: a literature review and a research agenda', Research Policy, Vol. 37, No. 4, pp.740-760.

Hunt, F. and Thornsbury, S. (2014) 'Facilitating transdisciplinary research in an evolving approach to science', Open Journal of Social Sciences, Vol. 2, 340.

Huutoniemi, K., Klein, J.T., Bruun, H. and Hukkinen, J. (2010) 'Analyzing interdisciplinarity: typology and indicators', Research Policy, Vol. 39, pp.79-88.

International Society for Transdisciplinary Engineering (ISTE) (2017) International Society for Transdiscplinary Engineering (ISTE) [Online]. Available: https://intsoctransde.org/?page_ $\mathrm{id}=17$ (Accessed 29 October, 2019).

IPCC (2014) 'Climate change 2014: mitigation of climate change contribution of working group III to the fifth assessment report of the intergovernmental panel on climate change', in Edenhofer O, Pichs-Madruga, R., Sokona, Y., Farahani, E., Kadner, S., Seyboth, K., Adler, A., Baum, I., Brunner, S., Eickemeier, P., Kriemann, B., Savolainen, J., Schlömer, S., von Stechow, C., Zwickel, T. and Minx, J.C. (Eds.), Cambridge University Press, Cambridge, UK and New York, NY, USA. 
IPCC (2019) 'Summary for policymakers. in: global warming of $1.5^{\circ} \mathrm{C}$. an IPCC special report on the impacts of global warming of $1.5^{\circ} \mathrm{C}$ above pre-industrial levels and related global greenhouse gas emission pathways, in the context of strengthening the global response to the threat of climate change, sustainable development, and efforts to eradicate poverty', in Masson-delmotte V, Zhai, P., PöRtner, H-o., Roberts, D., Skea, J., Shukla, P.R., Pirani, A., Moufouma-okia, W., Péan, C., Pidcock, R., Connors, S., Matthews, J.B.R., Chen, Y., Zhou, X., Gomis, M.I., Lonnoy, E., Maycock, T., Tignor, M. and Waterfield, T (Eds.), In Press.

Irvine, J. and Martin, B.R. (1984) Foresight in Science: Picking the Winners, London Frances Pinter.

Jantsch, E. (1947) 'Inter- and transdisciplinary university: a systems approach to education and innovation', Higher Education Quarterly, Vol. 1, pp.7-37.

Jantsch, E. (1970) 'Inter-and transdisciplinary university: a systems approach to education and innovation', Policy Sciences, p.1.

Johnson, J.L. and Hrynkow, S. (2011) Funding Agencies and Transdisciplinary Research, Springer, New York, NY.

Kessel, F. and Rosenfield, P.L. (2008) 'Toward transdisciplinary research: historical and contemporary perspectives', American Journal of Preventive Medicine, Vol. 35, pp.S225-S234.

Klein, J.T. (2014) 'Discourses of transdisciplinarity: looking back to the future', Futures, p.63.

Klein, J.T. and Falk-Krzesinski, H.J. (2017) 'Interdisciplinary and collaborative work: framing promotion and tenure practices and policies', Research Policy, Vol. 46, pp.1055-1061.

Lattanzio, S., Newnes, L.B., Mcmanus, M. and Hultin, A. (2019) 'Applying transdisciplinary engineering (TE) design research methodology to the challenge of managing decision support tool performance', Transdisciplinary Engineering Conference (TE2019), Tokyo, Japan.

Lawrence, R. (2010) 'Deciphering interdisciplinary and transdisciplinary contributions', Transdisciplinary Journal of Engineering and Science, Vol. 1, pp.125-130.

Lawrence, R. (2015) 'Advances in transdisciplinarity: epistemologies, methodologies and processes', Futures, Vol. 65, pp.1-9.

Lyall, C., Meagher, L. and Bruce, A. (2015) 'A rose by any other name? transdisciplinarity in the context of UK research policy', Futures, Vol. 65, pp.150-162.

Mowery, D.C., Nelson, R.R., Sampat, B.N. and Ziedonis, A.A. (2001) The growth of patenting and licensing by US universities: an assessment of the effects of the Bayh-Dole act of 1980', Research Policy, Vol. 30, pp.99-119.

Pettigrew, A.M. (1997) The Double Hurdles for Management Research, Dartmouth Press.

Pohl, C. and Hadorn, G.H. (2007) Principles for Desigining Transdisciplinary Research, Swiss Academies of Arts and Sciences.

Raab, W. (1966) 'Emotional and sensory stress factors in myocardial pathology. neurogenic and hormonal mechanisms in pathogenesis, therapy, and prevention', American Heart Journal, Vol. 72, pp.538-564.

Raasch, C., Lee, V., Spaeth, S. and Herstatt, C. (2013) 'The rise and fall of interdisciplinary research: the case of open source innovation', Research Policy, Vol. 42, pp.1138-1151.

Slaughter, S. and Leslie, L.L. (1997) Academic Capitalism: Politics, Policies, and the Entrepreneurial University, The John Hopkins University Press, Baltimore.

Stjepandic, J. (2019) 'The automatic generation of digital twins based on scanning and object recognition', Transdisciplinary Engineering Conference (TE2019), Tokyo, Japan.

Stjepandić, J., Wognum, N. and Verhagen, W.J.C. (2019) Systems Engineering in Research and Industrial Practice: Foundations, Developments and Challenges, Cham, Switzerland Springer.

Swiss Acadamies of Arts And Sciences (2018) Td-Net Networkd for Trandiscplinary Research [Online], Available: http://www.transdisciplinarity.ch/en/td-net/Ueber-td-net.html (Accessed 4 October, 2018). 
The University, O.F. and Bath (2018) TREND (Transdisciplinary Engineering Design) Research Group [Online]. Available: https://www.designbeyonddiscipline.com/about/ (Accessed 21 October 2019)

UK Government (2008) The Climate Change Act 2008(2050 Target Amendment) Order 2019.

UKRI (2019) Future Manufacturing Systems [Online], Available: https://epsrc.ukri.org/funding/ calls/future-manufacturing-systems/ (Accessed 21 October, 2019).

United Nations (2019) 2019 United Nations Framework Convention on Climate Change: The Paris Agreement [Online], https://unfccc.int/process-and-meetings/the-paris-agreement/the-parisagreement (Accessed 21 October 2019).

Wognum, N., Bil, C., Elgh, F., Peruzzini, M., Stepandic, J. and Verhagen, W.J.C. (2019) 'Transdisciplinary systems engineering: implications, challenges and research agenda', International Journal Agile Systems and Management, p.12.

Wognum, N., Bil, C., Elgh, F., Peruzzini, M., Stjepandić, J. and Verhagen, W. (2018) 'Transdisciplinary engineering research challenges', Proceedings of the 25th ISPE Inc. International Conference on Transdisciplinary Engineering, 2018 Modena, IOS Press, pp.753-762.

Ziman, Z. (2000) Real Science: What It is, and What It Means, Cambridge University Press, Cambridge.

Zscheischler, J. and Rogga, S. (2015) 'Transdisciplinary in land use science - a review of concepts, empirical findings and current practice', Futures, Vol. 65, pp.28-44. 